\title{
Prevalence of asymptomatic and symptomatic bacterial vaginosis in pregnant women attending antenatal clinic in a tertiary care rural hospital
}

\author{
Abhijit S. Ambike ${ }^{1}$, Yogendra Shelke ${ }^{2 *}$, Prasanna Nakhate ${ }^{2}$, Suvarna Patil ${ }^{3}$, \\ Charvi Sankholkar ${ }^{4}$
}

\begin{abstract}
${ }^{1}$ Department of Obstetrics and Gynecology, BKL Walawalkar Dervan, At Post Sawarda, Taluka Chiplun, District Ratnagiri, Maharashtra, India

${ }^{2}$ Department of Microbiology, BKL Walawalkar Rural Medical College and Hospital, Dervan, At Post Sawarda, Taluka Chiplun, District Ratnagiri, Maharashtra, India

${ }^{3}$ Medical Director, BKL Walawalkar Rural Medical College and Hospital, Dervan, At Post Sawarda, Taluka Chiplun, District Ratnagiri, Maharashtra, India

${ }^{4}$ III Year MBBS Student, BKL Walawalkar Rural Medical College and Hospital, Dervan, At Post Sawarda, Taluka Chiplun, District Ratnagiri, Maharashtra, India
\end{abstract}

Received: 16 June 2020

Accepted: 14 July 2020

\section{*Correspondence:}

Dr. Yogendra Shelke,

E-mail: dr.yogendra_shelke@rediffmail.com

Copyright: ( $)$ the author(s), publisher and licensee Medip Academy. This is an open-access article distributed under the terms of the Creative Commons Attribution Non-Commercial License, which permits unrestricted non-commercial use, distribution, and reproduction in any medium, provided the original work is properly cited.

\section{ABSTRACT}

Background: Bacterial vaginosis (BV) is one of the most common lower genital tract conditions, occurring in $35 \%$ of women attending sexually transmitted infection (STI) clinics, $15 \%$ to $20 \%$ of pregnant women, and $5 \%$ to $15 \%$ of women attending gynaecology clinic. It has been associated with serious pregnancy complications, including premature rupture of the membranes, preterm delivery and postpartum endometritis. The diagnosis of BV is usually based on clinical criteria including homogeneous vaginal discharge, an elevated vaginal $\mathrm{pH}$, the presence of clue cells, and an amine odour. Objective of this study was to study the prevalence of asymptomatic and symptomatic BV in pregnant women attending antenatal clinic in a tertiary care rural teaching hospital.

Methods: Sample size of 301 patients over 6 months study duration in an observational cross sectioned prospective type of study. An unfixed vaginal smear was collected from pregnant women and sent to microbiology for staining and fixing and diagnosis was established.

Results: The age range in pregnant women enrolled was 18 to 42 with mean age 26.10 years. As per the Nugent score criteria, 68 (23\%) women tested positive for BV (Nugent score 7-10) and 77 (25\%) had an intermediate score (Nugent score 4-6). While in 156 (52\%) pregnant women's Nugent score was in between 0-3 indicating no BV but $10 \%$ cases amongst these were showing presence of fungal elements mainly budding yeast cells with or without hyphae. In only $53 \%$ of cases of BV characteristic clue cells were present. In this study $69 \%$ cases of BV were observed in multigravida while $31 \%$ were present in primigravida.

Conclusions: Screening of asymptomatic pregnant women's by taking vaginal swab and evaluating gram smear using Nugent score system will play vital role early diagnosis of reproductive tract infections.

Keywords: Bacterial vaginosis, Clue cell, Nugent score 


\section{INTRODUCTION}

Bacterial vaginosis (BV) is a shift in the vaginal ecosystem characterized by an overgrowth of anaerobes, and a decrease in lactobacillus resulting in degradation of the natural flora that helps keep the vaginal tissue healthy. It is a very common infection in women, and there is a lack of understanding regarding the triggers and factors for its onset and resolution. BV is an important gynecologic problem of childbearing age group of women worldwide. The presence of BV has consistently been shown to be a risk factor for adverse obstetric outcomes such as preterm labor and delivery, preterm premature rupture of membranes, spontaneous abortion, and postpartum infections such as endometritis and caesarean section wound infections. It also increases the risk of HIV acquisition by approximately $60 \%$; because $\mathrm{BV}$ increases HIV genital shedding with in discharge and results in increased concentration of HIV in genital secretions, which in turn facilitates both vertical and sexual HIV transmission. ${ }^{1}$

The prevalence rates of BV among pregnant women vary from $6.4 \%$ to $38 \%$. It has been found that the lower the socioeconomic status of the population, the higher the incidences of bacterial vaginosis, which may indicate health and hygiene factors, play an even bigger role than anticipated. The methods of diagnosis used for diagnosis of BV can also have an effect on the variation of $\mathrm{BV}$ prevalence. The gold standard for diagnosis of $\mathrm{BV}$ is microscopic criteria proposed by Nugent. The clinical criteria by Amsel do not require laboratory facilities, specialized staff and there is no delay in reporting. However, it is difficult to evaluate all of these criteria for diagnosis of $\mathrm{BV}$ in busy practice; and it requires the ability of the gynecologist to analyse wet mount microscopy. ${ }^{2}$ Although many studies of $\mathrm{BV}$ have been done in different countries, currently author know of no published studies that have been conducted in a tertiary care rural teaching hospital, to describe the prevalence of $\mathrm{BV}$ among pregnant women. In order to avoid the above aforementioned pregnancy complications during BV infection, screening and treating of pregnant women is crucial. Therefore, the present study was carried out to determine the prevalence of $\mathrm{BV}$ and associated factors among pregnant women visiting antenatal clinic.

\section{METHODS}

This was an observational cross-sectional prospective study was carried out in the antenatal clinic (ANC) BKL Walwalkar Medical College and Rural Hospital, Dervan, Ratnagiri district between January 2020 to May 2020. Institutional ethics committee approval was taken. The study site is located in a remote and rural area of Konkan belt of Maharashtra. The hospital has an antenatal clinic which serves, on an average about 50 pregnant women each working day. The central clinical laboratory of authors institute runs routine test for the pregnant women, but the bacteriological procedures required for this study was carried out in the in department of microbiology. A total 301 as per the average attendance in the ANC clinic and appropriate statistical calculations.

\section{Inclusion criteria}

Inclusion criteria of this study was all pregnant women attending the antenatal clinic.

\section{Exclusion criteria}

Exclusion criteria of this study were all pregnant women not giving informed consent.

Patients history and complaints was noted on the OPD paper. Specimen collection was done by taking a vaginal smear of all the patients fitting in above criteria.

\section{Diagnostic criteria used}

There are two main categories of diagnostic tests for BV i.e. clinical criteria and laboratory-based testing.

The most widely accepted clinical criteria are 'Amsel's criteria'.

This clinical diagnosis requires that three of the following four criteria be met

- A vaginal $\mathrm{pH}$ of greater than $\mathrm{pH} 4.5$

- The presence of clue cells in the vaginal fluid

- A milky, homogeneous vaginal discharge

- Finally, the release of an amine (fishy) odour after addition of $10 \%$ potassium hydroxide to the vaginal fluid.

For the laboratory testing method, the preferred specimen is an unfixed vaginal smear sent to the laboratory to be gram stained by standard methods. The stained slide is read, and the number of morphotypes is evaluated based on a standardized scoring method.

In the methodology by Nugent et al the swab was obtained from the lateral vaginal wall and rolled on a glass slide. ${ }^{3}$ The smears are then heat fixed and Gram stained using safranin as the counterstain.

A score of zero to three is considered to be normal, four to six is considered intermediate, and seven to ten is defined as BV.

\section{In this study laboratory-based criteria were followed for diagnosis}

An unfixed vaginal smear was collected from pregnant women attending ANC clinic those pregnant women's who gave consent were enrolled. The collection was carried out by trained staff nurse under supervision of Obstetrician and swab was obtained from the lateral 
vaginal wall then it rolled/ spread on a clean glass slide to prepare an unfixed vaginal smear. These unfixed vaginal smears were sent to the microbiology laboratory for further processing.

In bacteriology section of microbiology laboratory, the smears were heat fixed and gram stained using safranin as the counterstain as per standard gram staining method. Then the smears were evaluated based on a standardized scoring method. The diagnostic criteria developed by Spiegel et al and later modified by Nugent et al has been a well-reproduced standardized gram stain scoring method which was used. Most of the pregnant women those were included in this study did not show any symptoms clinically.

\section{RESULTS}

Table 1 depicts the Nugent et al scoring method used in this study. The swab was obtained from the lateral vaginal wall and rolled on a glass slide. The smears are then heat fixed and gram stained using safranin as the counterstain. A score of zero to three is considered to be normal, four to six is considered intermediate, and seven to ten is defined as BV. As per above scoring method, smears were evaluated for presence of the following morphotypes under oil immersion (1000x magnification): large gram-positive rods (Lactobacillus morphotypes), small gram-variable rods ( $G$ vaginalis morphotypes), small gram-negative rods (Bacteroides species morphotypes), curved gram-variable rods (Mobiluncus species morphotypes) and Gram-positive cocci. Although gram-positive cocci are not part of the scoring system, Increased numbers of gram-positive cocci are not part of the pattern of the normal vaginal flora, so their presence was not reported.

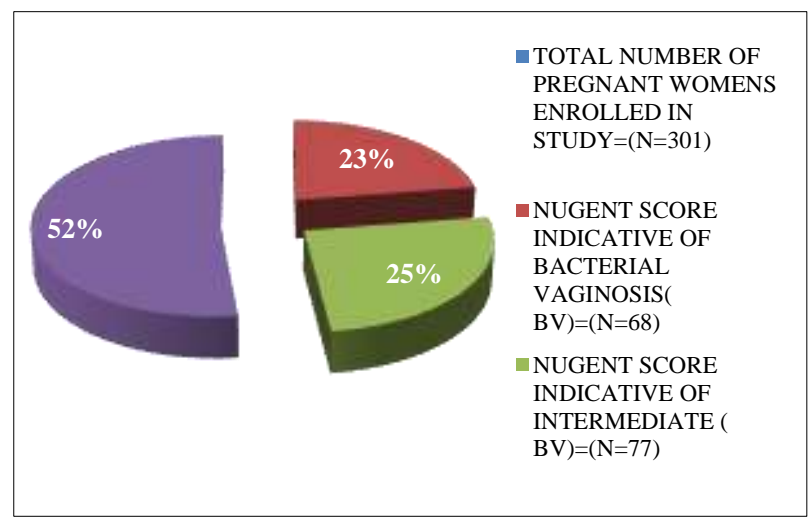

Figure 1: Percentage analysis of total enrolled cases as per Nugent score.

The total number of pregnant women enrolled in this study was 301 (Table 2). The age range in pregnant women enrolled was 18 to 42 with mean age 26.10 years. In this study $69 \%$ cases of BV were observed in multigravida while $31 \%$ were present in primi gravida.
Table 1: Nugent scoring method used in this study.

\begin{tabular}{|c|c|c|}
\hline Organism morphotype & $\begin{array}{l}\text { Number/oil } \\
\text { immersion field }\end{array}$ & Score \\
\hline \multirow{5}{*}{$\begin{array}{l}\text { Lactobacillus - like } \\
\text { (parallel sided, gram } \\
\text { positive rods) }\end{array}$} & $>30$ & 0 \\
\hline & $5-30$ & 1 \\
\hline & $1-4$ & 2 \\
\hline & $<1$ & 3 \\
\hline & 0 & 4 \\
\hline \multirow{3}{*}{$\begin{array}{l}\text { Mobiluncus - like } \\
\text { (curved, gram, } \\
\text { negative rods) }\end{array}$} & $>5$ & 2 \\
\hline & $<1-4$ & 1 \\
\hline & 0 & 0 \\
\hline \multirow{5}{*}{$\begin{array}{l}\text { Gordnerella/Bacteroids } \\
\text { - like (tiny, gram } \\
\text { variable coccobacilli } \\
\text { and pleomorphic rods } \\
\text { with vacuoles) }\end{array}$} & $>30$ & 4 \\
\hline & $5-30$ & 3 \\
\hline & $1-4$ & 0 \\
\hline & $>1$ & 1 \\
\hline & 0 & 0 \\
\hline
\end{tabular}

Total score: $0-3=$ Normal; $4-6=$ Intermediate, repeat test later; $7-10=$ Bacterial vaginosis

Table 2: Different age groups and gravida status and their relation with Nugent score.

\begin{tabular}{|c|c|}
\hline $\begin{array}{l}\text { Total pregnant women } \\
\text { enrolled in study }\end{array}$ & $\mathbf{N}=301$ \\
\hline \multicolumn{2}{|c|}{ Age groups in enrolled pregnant women's } \\
\hline 18 years - 24 years & $109 ¥(24 \%)$ d \\
\hline 25 years - 30 years & $146 ¥(33 \%)$ : \\
\hline$>30$ years & $46 ¥(11 \%) \not$ \\
\hline Range of age (in years) & $18-42$ \\
\hline Mean age (in years) & 26.1 \\
\hline Nugent score S/O BV & 68 cases \\
\hline $\begin{array}{l}\text { Multigravida amongst } \\
\text { diagnosed BV cases }\end{array}$ & $47(69 \%)$ \\
\hline $\begin{array}{l}\text { Primi gravida amongst } \\
\text { diagnosed BV cases }\end{array}$ & $21(31 \%)$ \\
\hline
\end{tabular}

Note: ¥: number of pregnant women enrolled in particular age group, number in bracket indicating number of positive cases as per Nugent score

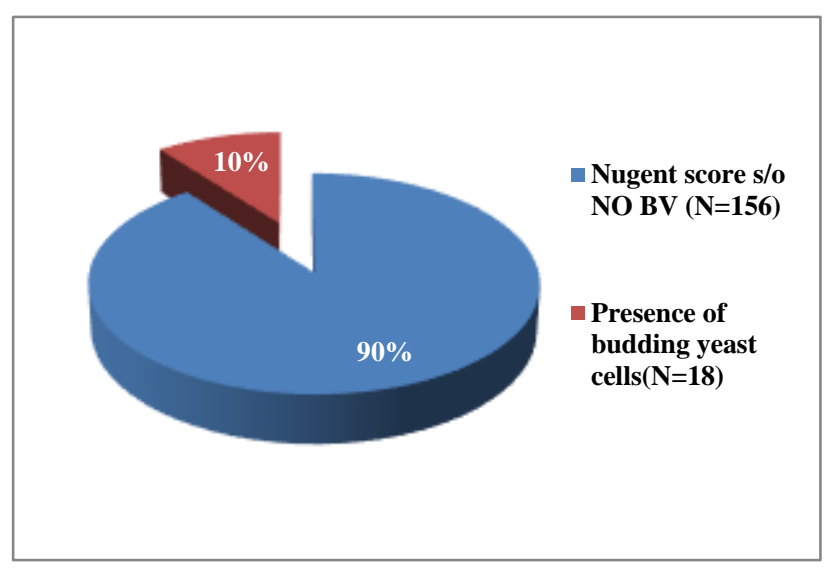

Figure 2: Budding yeast cell among cases not indicating BV on basis of Nugent score. 
As per the Nugent score criteria, $68(23 \%)$ women tested positive for BV (Nugent score 7-10) and 77 (25\%) had an intermediate score (Nugent score 4-6) (Figure 1).

While in $156(52 \%)$ pregnant women's Nugent score was in between 0-3 indicating no BV but $10 \%$ cases amongst these were showing presence of fungal elements mainly budding yeast cells with or without hyphae (Figure 2).

Out of the 68 cases of BV, 53 cases were in third trimester of pregnancy, in second trimester 14 cases were reported and only a single case was reported in first trimester (Figure 3).

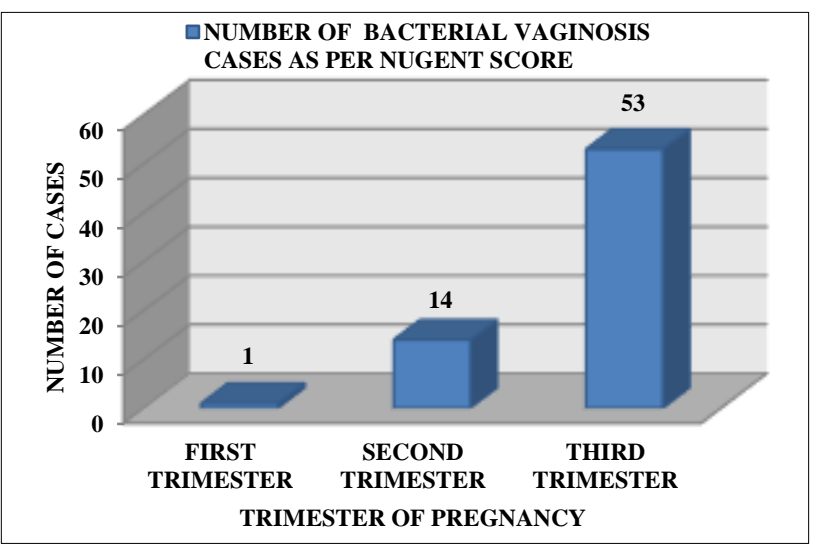

Figure 3: Number of cases of bacterial vaginosis per trimester of pregnancy.

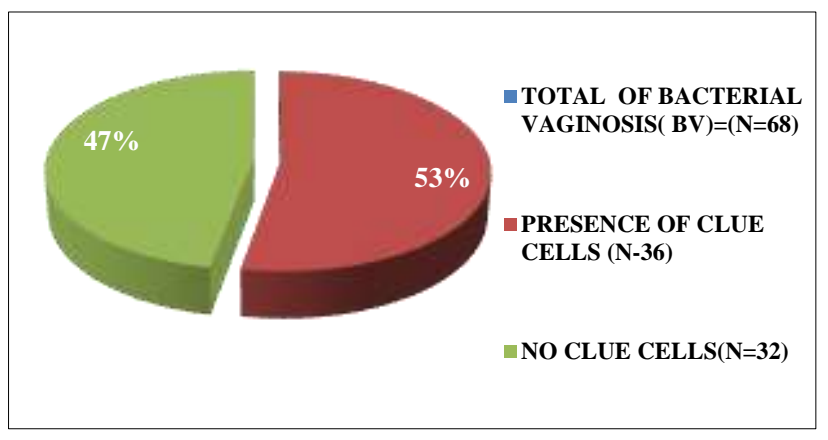

Figure 4: Percentage of presence or absence of clue cells in bacterial vaginosis cases.

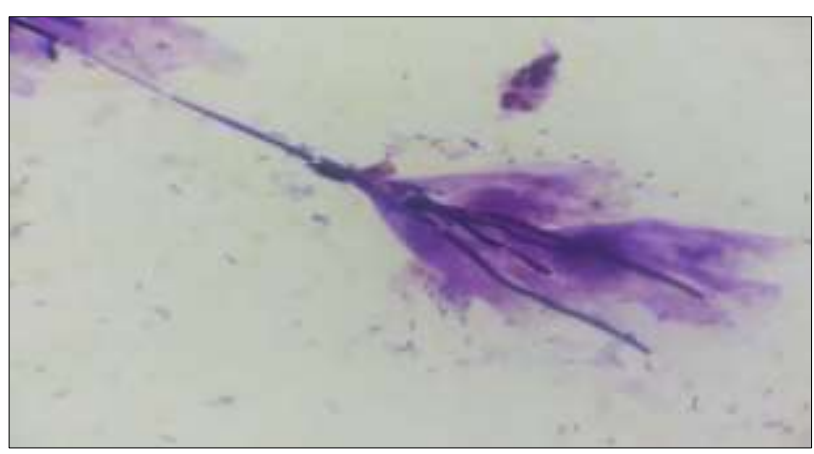

Figure 6: Histopathological of fungal hyphae seen in a few smears in this study.
Out of total 68 cases of BV, only $53 \%$ cases showed presence of clue cells which is diagnostic of BV and the remaining 47\% did not show clue cells (Figure 4).

While in $156(52 \%)$ pregnant women's Nugent score was in between 0-3 indicating no BV but $10 \%$ cases amongst these were showing presence of fungal elements mainly budding yeast cells with or without hypha.

\section{DISCUSSION}

The diagnosis of BV is usually based on clinical criteria including homogeneous vaginal discharge, an elevated vaginal $\mathrm{pH}$, the presence of clue cells, and an amine odor. Authors have evaluated the vaginal flora and clinical signs for 301 pregnant women. As per the Nugent score criteria, $68(23 \%)$ women tested positive for BV (Nugent score 7-10) and 77 (25\%) had an intermediate score (Nugent score 4-6) similar to Nugent study. ${ }^{3}$ While in $156(52 \%)$ pregnant women's Nugent score was in between $0-3$ indicating no BV but $10 \%$ cases amongst these were showing presence of fungal elements mainly budding yeast cells with or without hyphae indicative of fungal infection which was not seen in many studies.

Bacterial vaginosis is a commonly encountered cause of vaginitis. The average incidence of $\mathrm{BV}$ varies; the rates are $10-35 \%$ in patients visiting gynecological wards, 10 $30 \%$ in patients visiting obstetric wards and $20-60 \%$ in patients visiting services of sexually transmitted disease. ${ }^{4}$ The prevalence of $\mathrm{BV}$ in this study is $23 \%$ which is similar to one study carried out in Ethiopia by Mengistie et al which is $19.4 \%$, however it is lower as compared to other similar studies carried out by Mathew et al and Bhalla et al in their studies which they found $38.5 \%$ and $32.8 \%$ respectively. ${ }^{5-7}$

The presence of clue cells detected in a wet preparation of vaginal fluid also correlated very well with a clinical diagnosis of BV. This is not surprising, since the presence of clue cells was one of the four criteria used to define BV clinically in this study similar to an old study by Carol et al and clinical evidence 2005 study. ${ }^{8,9}$ The age range in pregnant women enrolled was 18 to 42 with mean age 26.10 years which is similar to many other studies conducted. ${ }^{10,11}$ In this study $69 \%$ cases of BV were observed in multigravida while $31 \%$ were present in primi gravida, reason being laxity of the vaginal wall in multigravida which exposes the mucosa to infection easily.

\section{CONCLUSION}

Screening of asymptomatic pregnant women's by taking vaginal swab and evaluating gram smear using Nugent score system will play vital role in early diagnosis of reproductive tract infections. Culture also has its role but in resource constraint settings like ours, gram staining and Nugent score system-based analysis may act as a 
crucial component in early detection of $\mathrm{BV}$ in asymptomatic pregnant women.

Funding: No funding sources Conflict of interest: None declared

Ethical approval: The study was approved by the Institutional Ethics Committee

\section{REFERENCES}

1. Mengistie Z, Woldeamanuel Y, Asrat D, Adera A. Prevalence of bacterial vaginosis among pregnant women attending antenatal care in Tikur Anbessa University Hospital, Addis Ababa, Ethiopia. BMC Res Notes. 2014;7(1):822.

2. Joyisa N, Moodley D, Nkosi T, Talakgale R, Sebitloane M, Naidoo M, Karim QA. Asymptomatic bacterial Vaginosis in pregnancy and missed opportunities for treatment: a cross-sectional observational study. Infect Dis Obstet Gynecol. 2019; ArticleID:7808179.

3. Nugent RP, Krohn MA, Hillier SL. Reliability of diagnosing bacterial vaginosis is improved by a standardized method of gram stain interpretation. J Clin Microbiol. 1991;29:297-301.

4. Mengistie Z, Woldeamanuel Y, Asrat D, Adera A. Prevalence of bacterial vaginosis among pregnant women attending antenatal care in Tikur Anbessa University Hospital, Addis Ababa, Ethiopia. BMC Res Notes. 2014;7:822.

5. Tokyol Ç, Aktepe OC, Cevrioğlu AS, Altındiş M, Dilek FH. Bacterial vaginosis: comparison of Pap smear and microbiological test results. Modern Pathol. 2004;17(7):857-60.

6. Mathew R, Kalyani J, Bibi R, Mallika M. Prevalence of bacterial vaginosis in antenatal women. Indian $\mathrm{J}$ Pathol Microbiol. 2001;44(2):113-6.

7. Bhalla P, Chawla R, Garg S, Singh MM, Raina U, Bhalla $R$, et al. Prevalence of bacterial vaginosis among women in Delhi, India. Indian $\mathrm{J}$ Med Res. 2007;125(2):167-72.

8. Spiegel CA, Amsel R, Holmes KK. Diagnosis of bacterial vaginosis by direct gram stain of vaginal fluid. J Clin Microbiol. 1983;18(1):170-7.

9. Joesoef MR, Schmid G. Bacterial vaginosis. Clin Evid. 2005;13:1968-78.

10. Gellar M, Nelson A. Diagnosis and treatment of recurrent and persistent vaginitis. Womens Health Gynecol. 2004;4:137-46.

11. Nelson DB, Macones G. Bacterial vaginosis in pregnancy: current findings and future directions. Epidemiol Rev. 2002;24:102-8.

Cite this article as: Ambike AS, Shelke Y, Nakhate P, Patil S, Sankholkar C. Prevalence of asymptomatic and symptomatic bacterial vaginosis in pregnant women attending antenatal clinic in a tertiary care rural hospital. Int J Reprod Contracept Obstet Gynecol 2020;9:3672-6. 